\title{
Sources and flow of healthcare built environment design evidence
}

*Nadeeshani Wanigarathna

Department of Engineering and the Built Environment, Anglia Ruskin University, City, UK Bishop Hall Lane, Chelmsford CM1 1SQ.

Nadeeshani.wanigarathna@aru.ac.uk

Fred Sherratt

Department of Engineering and the Built Environment, Anglia Ruskin University, City, UK Bishop Hall Lane, Chelmsford CM1 1SQ.

Fred.Sherratt@aru.ac.uk

Andrew Price

School of Civil and Building Engineering, Loughborough University, City, UK Epinal Way, Loughborough LE11 3TU.

A.D.F.Price@ @lboro.ac.uk

Simon Austin

School of Civil and Building Engineering, Loughborough University, City, UK Epinal Way, Loughborough LE11 3TU.

S.A.Austin@lboro.ac.uk

\section{Acknowledgements}

Authors wish to acknowledge who participated in the interviews, case studies and industry partners who supported the research overall.

\section{Funding details}

This work was supported by the [Loughborough University ESPRC IMCRC] under Grant [number EP/E002323/1]; and [EPSRC] under Grant [numbers EP/D039614/1 and EP/I029788/1].

\section{Disclosure statement}

No potential conflict of interest was reported by the authors. 


\section{Sources and flow of healthcare built environment design evidence}

\section{Abstract}

Purpose: A substantial amount of research argues that built environmental interventions can improve the outcomes of patients and other users of healthcare facilities, supporting the concept of Evidence-based design (EBD). However, the sources of such evidence and its flow into healthcare design is less well understood. This paper aims to provide insights as to both the sources and flow of EBD used in three healthcare projects, to reveal practicalities of use and the relationships between them in practice.

Design/ Methodology/ Approach: Three healthcare case study projects provided empirical data on the design of a number of different elements. Inductive thematic analysis was used to identify the source and flow of evidence used in this design, which was subsequently quantizised to reveal the dominant patterns therein.

Findings: Healthcare design teams use evidence from various sources, the knowledge and experience of the members of the design team being the most common due to both ease of access and thus flow. Practice based research and peer reviewed published research flow both directly and indirectly into the design process, whilst collaborations with researchers and research institutions nurture the credibility of the latter.

Originality: This research contributes to understandings of EBD by exploring the flow of research from various sources in conflation and within real life environments.

Implications: The findings can be used to enhance activities that aim to design, conduct and disseminate future EBD research to improve their flow to healthcare designers.

Keywords: Evidence-based design, flow of evidence, design evidence sources, healthcare 


\section{Introduction}

The importance of design in enabling healthcare built environments to achieve improved health performance outcomes is being increasingly recognised (Charis et al., 2007), and has resulted in the establishment of Evidence-Based Design (EBD) as an accepted approach in the sector. The intention of $E B D$ is to improve healthcare performance through the use of evidence in the design process that demonstrates how built environment interventions can positively influence the outcomes of the healthcare users. However, the evidence that underpins EBD can arguably come from a number of sources, and there is ongoing debate as to what constitutes credible research that is able to validate and indeed warrant the label of 'evidence' (see Stichler, 2010; Moore \& Geboy, 2010, for example). However, despite such debates, it is generally understood (and accepted for the purposes of this paper) to be evidence grounded in peer-reviewed, scientific enquiry using the '...most up to date credible research conducted according to the highest standards of rigour appropriate for that given research approach....' (Moore \& Geboy 2010), with the capacity for practical and experiential enhancements to be made alongside (e.g. Hamilton \& Watkins 2009).

Yet despite increasing volumes of published evidence of this nature, the progress of EBD into practice although positive, is arguably not impressive. Although Hamilton (2018, pp. 34) in a recent review claimed that EBD for built environments has become 'an accepted norm if not best practice' in healthcare, it was also noted that relatively few EBD features identified through peer-reviewed research have actually achieved the consensus of 'best practice' in reality. Weaknesses within the EBD evidence itself and its forms, as well as more generic design constraints, have been suggested to limit designers' use of peer reviewed published evidence (Elf et al., 2015; Codinhoto et al., 2010, Hamilton, 2010; Neuckermans \& Fontein, Emmitt, 2007). Furthermore, it has also been claimed that the methods that underpin EBD remain predominantly theoretical, in large part because it they not yet been fully adopted and evaluated 'in-use' (Elf et al., 2015). For instance, widely adopted EBD interventions such as private patient rooms in hospitals and decentralisation of nurses' base are not without criticisms (Taylor et al., 2018; Voigt et al., 2018; Fay et al., 2019). 
However research exploring this phenomenon, asking why EBD has not been more widely adopted by practice, has arguably itself struggled to provide insights able to bring about positive change, in part due to the siloed nature of such investigations. The main streams of investigation relate to: improving the direct intake of peer-reviewed published evidence (e.g. Martin \& Guerin, 2007; Stichler, 2010; Pati, 2011); promoting designer-involved research at project or organisational levels to generate evidence internally (Becker \& Carthers, 2007; Freihoefer \& Zborowsky 2017); and enhancing evidence based healthcare design standards and guidance (Mills et al., 2015). Yet these approaches do not allow for the consideration of EBD as part of a holistic process undertaken in a lived reality. It is designers who ultimately decide when, how, or even whether to draw on different sources of EBD at all during the design process, whilst also being influenced and/or constrained by the lived contexts and other externalities that can facilitate or hinder EBD. This study aims to contribute to enhanced understandings of this process by presenting empirical case study research that explored both the sources (EBD or not) and flow (here defined as the mechanisms and means by which such sources came into the design) of evidence within three healthcare projects.

Examining EBD in this holistic way enables consideration of the full range of design evidence in use within real contexts, producing findings with strong ecological validity able to better illuminate current barriers to uptake, reveal how EBD is used in practice, and thus support the ambitions of more focused research as noted above, and ultimately enhance the use of EBD in practice to support improved healthcare design and consequentially healthcare outcomes for patients.

\section{Source and Flow Issues in the Uptake of EBD}

Previous research has suggested that the slow progress of EBD into practice is associated with a number of factors relating to both sources and flow. Issues include weaknesses within the evidence base, contextual constraints, and the ways in which research based evidence is and can be used in practice. Individually, and more realistically, in conflation, such factors hinder and suppress the flow and use of research based evidence in healthcare design, and thus the use of EBD in practice overall. 
The first key issue surrounds the format of the evidence itself as a source, as it is found in peerreviewed, academic journals which are not easily accessible to designers (Hamilton, 2007; Codinhoto et al., 2010). Academic journal evidence base has also been considered by some to be both incomplete and immature (Stankos \& Schwarz, 2007), often not presented in forms and formats that can be easily understood and interpreted by designers (Martin \& Guerin, 2007; Lawson, 2010; Chen et al., 2011), written as they are for fellow academics (Martin \& Guerin, 2007). The Health Environments Research and Design Journal (HERD) is a dedicated peer reviewed research journal that publishes EBD evidence as well as EBD procedural guidance. However this subscribed publication can only publish a limited volume of research, thus the majority of EBD research remains scattered across various built environment and clinical journals.

A second key issue is the context in which the use of EBD must occur which can seriously hinder its flow. The time needed to read, digest and synthesis academic literature is extensive (Lawson, 2010), and the time and costs (which can be considerable) required to access published research is rarely paid for by clients (Hamilton, 2010). Such contexts are critical as design teams work with resource constraints, often to tight time scales with large workloads (Grol \& Grimshaw 2003; Martin \& Guerin, 2007; Sailer et al., 2010), which limits their ability to search and use research in general as there is a perceived need to safeguard project hours for other tasks during the design process (Codinhoto et al., 2010). Although the evidence may be present, it is unable to flow due to such constraints. It has also been suggested that designers lack the necessary training and skills for the utilisation and understanding of the sources in the form of published peer reviewed research (Hamilton 2010; Martin \& Guerin, 2007; Devlin \& Arneill, 2003) or the skills for searching appropriate literature (Edelstein, 2008) which typically does not emerge using simple keyword searches (Martin \& Guerin, 2006) and again has the potential to limit flow. This issue is further compounded by the fact that the healthcare building designs are complex and involve large numbers of design elements and decisions, so to effectively review the available literature on such a scale requires a considerable amount of time (Codinhoto et al., 2010). 
Thirdly, the design of a building is different from any other design product, and indeed is often highly complex. Therefore, evidence generated in one context may not always suit the design problem in the next (Becker \& Carthers, 2007; Crocker, 2020), potentially making the source redundant as well as hindering its flow. For example, Ulrich et al. (2010) presented types of built environment variables and resultant user and organisational outcomes which need to be considered during design. Wanigarathna et al. (2019) explained how patient demographics, care models of hospitals, local departmental needs, and facility operational aspects should be considered whilst adopting existing design features into a new situation. Furthermore, peer reviewed published evidence has limited opportunity (more practically, space for the words) to present important considerations such as the project context and evolutionary history of design solutions, which influence the effectiveness of design re-use (Demian \& Fruchter, 2006). This is a fundamental problem with the source itself, and again directly influences its ability to flow (or not) into appropriate new spaces. Despite the fact that built environment design problems are multifaceted (Lawson, 2010), much research evidence tends to be parametric, focusing on individual issues such as lighting. Designers are therefore not in a position to simply 'cut and paste' best practice or features from the past (Kamara et al., 2003; Moore \& Geboy, 2010) and particularly for healthcare, the translation of evidence has remained a challenge (Nanda \& Wingler, 2020).

Finally, and perhaps most fundamentally, the nature of designers' preferred ways of knowing and practicing design has an impact on the EBD practices (Evans, 2009; Lawson, 2004). It is often claimed that published research is not a primary source of evidence when designing (Emmitt, 2007; Neuckermans \& Fontein, 2002).

\section{Enhancing EBD in Practice}

The literature reveals three distinct approaches in the attempts to improve the uptake of EBD in practice, each of which are explored in more detail in turn below:

1) eliminating problems associated with the use of published peer reviewed research evidence, thus to improve the direct intake of such evidence; 
2) promote designer-involved internal research at project or organisational level (including supply chain organisations); and

3) produce and update evidence informed healthcare design standards and guidance.

A number of attempts have been made or proposed to (1) improve the direct intake of published peer reviewed research evidence, which have gained the attention of EBD researchers. Summarising peer reviewed published research into databases in designer friendly language and formats has been undertaken, resulting in established databases including: Pebble project evidence (Center for Health Design, 2020); InformeDesign Database (Martin \& Guerin, 2006); the Environmental Evidence Database produced by Sheffield University, and the Department of Health (DH) UK in the year 2006 (Phiri, 2006). However, such databases always face the ongoing challenge of maintenance and update with new evidence (Mills et al., 2015) which can impact their credibility as sources. For example, the InformeDesign Database for example has not been available since mid-2019.

An alternative approach by other researchers has been to conduct systematic reviews of published peer reviewed evidence of healing environments to better facilitate dissemination (Phiri et al., 2006; Ulrich et al., 2008; Codinhoto et al., 2009; Huisman et al., 2012; Brambilla \& Capolongo, 2019; Zhang et al., 2019; Taylor et al., 2018; Voigt et al., 2018). For example, in their systematic review of published research, Zhang et al. (2019) summarised the relationships between built environment interventions and the physical outcomes, Psychological perception and life experience of healthcare users. Whilst Ulrich et al. (2010) highlight the relationships of how healthcare built environments can impact patients and their families, staff and organizational outcomes. In addition, a number of systematic reviews have been conducted around a particular space, care setting or a particular patient category, for example Bartlett (2013) reviewed research evidence related to design features that can be used to create an optimal inpatient psychiatric patient, whilst Taylor et al. (2018) and Voigt et al. (2018) have reviewed evidence related to the benefits of private-patient rooms, and Benitez, et al. (2019) conducted a systematic review on layout planning in Healthcare Facilities. 
When considered alongside the many individual pieces of published EBD research scattered across number of publications, such systematic reviews seem to be more popular among both researchers and practitioners, and have created an increased awareness about EBD through their comprehensive approach.

Decision support frameworks developed through systematic reviews have also been considered a good alternative strategy to pass evidence into the design process (Van-Hoof et al. (2015) and the reviews undertaken by Ulrich et al. (2008) and Codinhoto et al. (2009) were converted into simple decision support frameworks which could be shared with the design community through design conferences and similar means. These frameworks only guide designers of the implications of design interventions, leaving the identification and application of evidence the responsibility of the design teams themselves. Stichler (2010), drawing on evidence-based medical literature, presented a framework to help designers evaluate the credibility of evidence before use. Furthermore, Pati (2011) drawing on design research, also proposed a framework and detailed guidance to evaluate the credibility of peer reviewed published evidence gleaned through quantitative and qualitative researches. Encouraging design professionals to collaborate with experts in research, and so seek new skills for searching, interpreting and applying evidence to design (Edelstien, 2008) have also been suggested as fruitful ways forward for the increased use of EBD.

An alternative approach is to involve design teams in the research that underpins EBD (2). Whilst some researchers do not agree that the design practitioners' research is credible enough to constitute evidence for EBD (Stankos \& Schwarz, 2007), considering the unique and complex nature of healthcare built environment designs many EBD researchers actually conclude that that best evidence is that generated by practice (Hamilton and Watkins, 2009) or from practice based research (Becker \& Carthers, 2007; Freihoefer \& Zborowsky 2017). Zborowsky \& Bunker-Hellmich (2010) claim that alongside their colleagues in academia, practice-based researchers (design practitioners) can participate in expanding the existing EBD knowledge base. Codinhoto et al. 
(2010) recommended employing a researcher or external party within the design team to provide research skills and conduct the research, and also developed a framework which guides designers, or those with fewer skills and experience of how to gather evidence for EBD, in their in literature searches. Hamilton (2003) in his unarguably optimistic 'Four Levels of Evidence-Based Practice' model presents a similar concept. He expects that EBD practitioners would first start using EBD evidence and design features in their designs (level 1) and move onto hypothesize the expected outcome associated with the evidence-based concept and measuring the effectiveness of using such design features (level 2), reporting application results publicly with a larger design community (level 3) and finally in peer review journals (level 4). In addition, several researchers have developed tools to aid design teams to conduct practice-based research and generate new evidence. For example, Freihoefer \& Zborowsky (2017) investigated how a researcher could be employed within design teams to implement EBD interventions as mean of practice based research. Authors also claims that this could improve design professions' body of knowledge. Further, in order to eliminate the weaknesses associated with the retrospective nature of postoccupancy evaluation, Nanda \& Wingler (2020) introduced a composite tool called 'Design Diagnostic' to promote research-based design practices. Diagnostics enable designers and clients to collect and interpret observed, reported and spatial data collected through a range of means such as surveys, interviews, behavioural mapping in order to generate new useful evidence to support EBD. Mock-up simulations such as enhanced traditional mock-ups and the newer techniques such as, rapid prototyping, early build-out, virtual reality has been identified as a way of testing EBD evidence as well as to generate new evidence (Watkins et al., 2008: Cited in Durham and Kenyon, 2020). Durham \& Kenyon (2020) provide detail guidance on how to select a suitable mock-up technique to understand, test, and revise the proposed physical space before the design and construction. In addition, material and component producers carry out the majority of construction-related research and these could benefit designs (Gann et al., 1998), with the improved communication between them and design teams (Larsson et al., 2006). These duly 
tested EBD interventions via practice based research can then adopted by other practitioners as a 'safe' design choice which eventually becomes a consensus best practice (Hamilton, 2018). Involvement of non-design professionals such as clinical staff and users can however be challenging due to the broad nature of their views, difficulties in reading design material and due to lack of structured approaches and thus result in limited benefits (Hignett \& Lu, 2009).

Finally, credible research based evidence could be passed onto the design process through design standards and guidance (3). There is a large amount of regulation and guidance for healthcare designing (Hignett \& Lu 2009) and design evaluation tools published by governments and professional institutions. Healthcare designing in the UK is governed by a long established centrally issued (commissioned by the $\mathrm{DH}$ and now found on gov.uk) set of design standards and guidance. Health Building Notes (HBNs) and Health Technical Memoranda (HTMs) form the key guidance for healthcare design, and are increasingly becoming evidence-informed. They are often termed as evidence-based standards and guidance, yet such evidence is generated through a mixture of practice-based research, best practice from the industry and least of all, published peer reviewed research evidence. The popularity of EBD practices has seen a strong desire to share EBD interventions via design standards and guidance. For example, 'HBN 04-01 adult in-patient facilities' has incorporated evidence (EBD) in relation to the benefits of private-patient rooms. More recently, 'HBN 08-02 Dementia-friendly Health and Social Care Environments' shares best practice evidence from the DH Capital Investment Programme funded 115 health and social care pilot projects. In addition, ASPECT (DH, 2008), is a healthcare design evaluation tool developed and based on a therapeutic evidence review undertaken by Phiri (2006) and published by the DH. Yet whilst standards and guidance provide a clear opportunity to facilitate EBD into practice, they also possess their own weaknesses to overcome as well. These include: the large amount of uncoordinated regulation and guidance, implications of designers freedom, (Hignett \& Lu, 2009) issues associated with duplication, fragmentation, non-standardisation (LaFratta, 2006) and challenges related to maintaining and updating these centrally commissioned design standards 
guidance in times of limited capital investment (Mills et al., 2015). Mills et al. (2015) explained the need for a wider ownership of building design quality standards throughout the supply chain, with interdisciplinary expertise and in order to eliminate above mentioned challenges and to facilitate nationwide learning and improvements in evidence and outcomes.

\section{Summary: the SaFE Model}

To summarise, Figure 1 below conceptualises how the different sources of evidence flows into the healthcare design process as identified through the literature. Type A and B evidence is that found in (2) above sources explained above were separated into to two categories to distinguish between project specific evidence generation and other evidence generated at supply chain partner organisations ; Type $C$ is that found in (1), whilst Type $D$ is that found in (3). The more nuanced issues that surround each Type of evidence, and the attempts to mitigate their impact in practice, are as discussed above.

[Insert Figure 1 near here]

Figure 1 has also been verified and validated via interviews with EBD academics ( 5 No) and EBD practitioners (12 Nos) as part of the wider research that underpins this paper (Authors et al., 2012).

\section{Research Methods}

This study aims to provide enhanced understandings of this process by presenting empirical case study research that explores both the sources and flow of evidence within three healthcare projects. Due to the exploratory nature of this research, an interpretivist epistemology was mobilised, best able to support the collection and coherent analysis of a variety of qualitative data from the case study projects. Such an approach enables the nuance and subtler elements of practice to be revealed, and thus illuminate how evidence from a range of sources flowed into the designs, including the extent and rationale of their uses in different contexts and under various circumstances, with due consideration of the externalities also involved. 


\section{The Case Studies}

The selection of the three case studies followed Yin (2009)'s approach to multiple cases (three hospital design projects) with multiple embedded unit of analysis (comparable design elements) within each case. Three recently completed healthcare building projects (Case studies 1, 2 and 3) were chosen from industry partners of the research project. All three case study projects were planned and designed when EBD had a high profile amongst healthcare stakeholders, and when some EBD features were enforced by DH UK best practice design guidance.

Case study 1 was a large scale (circa $f 88 \mathrm{M}$ ) project involved design and construction of new wing for an existing children's hospital. Case Study 2 was a large scale (circa $f 90 M)$ project and a new noncritical elderly care and mental health hospital which was designed to replace a number of existing small hospitals serving a region within the UK. Case Study 3 was a medium scale (Circa $f 10 \mathrm{M}$ ) project, an elderly care facility built within a short time frame to help with forthcoming (then) winter pressure for an existing hospital. Case study 3 was particularly useful to gain the details of evidence gathering and utilisation in time restricted scenarios.

\section{Data Collection and Analysis}

Figure 2 below details the steps of the data collection and analysis process. This was complex and contained a number of different steps to enable the distillation of relevant units of analysis for further examination.

[Insert Figure 2 near here] Step 4 collected data using semi-structured interviews through a series of 10, 2-3 hour long interviews with the lead designer, the lead engineering service designer, a client representative involved in the design process and a client representative to comment about the in-use phase of the hospital. Each interviewee was asked to explain the design development process and the details of evidence use for each of the design element in a story telling manner. Story telling or narrative nature discussions enabled interviewees to immerse back into their design experience retrospectively and explain it with rich details as if they were gone back in time. In addition, 
documentary data such as business cases, presentations and various other reports related to the design development were also collected.

Step 6 comprises the final data analysis, and itself comprised a number of sub-steps. This study employed both quantitative and qualitative analytical methods. Firstly, it involved the creation of 'Design Stories' for each individual design elements. Design stories are the narrative of the design process for each element, based on multiple sources of evidence including the interview and documentary data. They comprised details of the steps/activities followed by the design team, and the evidence used at the each step/activity, to take the design from the initial conceptual design to the final approved design. In some cases, follow up telephone calls were made by the researcher to fill any gaps in the stories.

These design stories were then themselves thematically analysed to identify the sources of evidence (inductive themes) used at each design step and establish a set of key evidence sources used by healthcare design teams. This analysis revealed 8 key sources of evidence related to types $A, B C$ and D from the SaFE model. Content analysis was then applied to the data to determine the extent/frequency of evidence use from the key sources identified above. Quantitative content analysis of qualitative data typically involves statistical procedures, tools that summarise data in order to recognise patterns (Riffe et al., 2019). This analysis is not an objective 'search and count' of key words as would be undertaken in traditional content analysis as this would not find fit with the underpinning methodology employed here. Instead, the researcher carefully read each design story to manually record the source and flow of evidence behind each stage in each design story, in a quantizised interpretation of the results. Simple descriptive statistics were then used to calculate the frequency use of each type of evidence source within each case study. Each instance of use of an evidence source identified within design stories was counted as one. For example, the design story for the decentralised nurse base layout for the Case Study 1 indicated 11 instances of evidence uses, from knowledge and experience (4 instances), user consultation ( 2 instances), external research ( 3 instances) and visits to other facilities ( 2 instances). These numbers were then used to 
calculate the \% use each source of evidence within each case study to simply demonstrate the patterns found therein. Finally, sense making of raw data and the results of the two steps above assisted in the enhanced understanding of the rich contextual information and insights as to the flow of evidence in different settings, together with their context and subsequent application. The internal validity of the findings and analysis were primarily achieved through the triangulation of data from the multiple sources as explained above, supported by inter-reader reliability secured through cross-checking of findings and analysis by the other authors of this paper. That each design element was formed of data from multiple parties involved in the projects also provides a measure of ecological validity for the project.

\section{Findings and Discussion}

Thematic analysis of the case study data revealed 8 key sources of evidence related to types $A, B C$ and $D$ (as conceptualised within the SaFE Model) that were used by the healthcare designers. They are: Knowledge and experience; Internally generated evidence; Evidence from the industry; User consultation; Standards and guidance; Visits to facilities; Peer reviewed published research (EBD) and Expert opinion. Some sources of evidence (e.g. user consultation) could have been assigned to different categories, depending on the project circumstances. For instance, Case Studies 1 and 3 had the benefit of Type A user consultation evidence through their existing staff and patients, whilst Case Study 2 was a new hospital and so could only consult the local general public as prospective patients. In addition, 'expert opinion' in reality contributed a mix of Type B and C evidence. This suggests that the flow of consultation evidence is itself dependent on externalities, and is not restricted to the type of evidence under consideration.

The frequency of evidence use from different sources can be seen in Figure 3, as a percentage of total use for ease of communication. Some design decision making steps were supported by multiple sources of evidence, and these were separately recognised as 'use in combination with other sources' during this analysis. 1,2 and 3 labels for each bars on the graphs refer to data for case 
studies 1,2 and 3 respectively. This indicates that the flow of such evidence is likely to be a 'messy' process in which sources flow in different ways into the design, and indeed may themselves catalyse or unblock the flow of additional and alternative sources as the process continues.

[Figure 3 near here]

To better illustrate the use of evidence from sources other than K\&E, this was omitted from the data set in the creation of Figure 4.

[Figure 4 near here]

Using private rooms design as an example, Table II shows the flow of published and other researchinformed evidence in to the design of Case Studies 1 and 2. Due to the time constraints, the Case study 3's use of private patient room design was a re-use of a recently competed private room design by the same design team. Details of the sources of evidence for the original design were not identified within this research.

[Table I near here]

In all three Case Studies, evidence from knowledge and experience (K\&E) dominated, and was used throughout the design process within almost every type of activity, also suggesting the easiest flow into design in practice. Although this is unsurprising given the nature of the source itself, this research provides empirical validation of that assumption. Interestingly, this is the one source that does not itself require any external mechanism to instigate or lubricate its flow, as it is inherent within the designers and their teams. K\&E was used to evaluate evidence from other sources; as a complementary source of evidence for project-unique design problems; and to support design decisions where no or limited evidence was available from other sources (e.g. fast-track design for Case Study 3). Findings also reveal that K\&E itself represents an accumulated store of historically accessed evidence through all other sources and thus somewhat research informed, yet more research is required to investigate its content and credibility. 


\section{Published Peer-Reviewed Research}

Peer reviewed published research was the least used source within the design process in terms of frequency of use. Peer reviewed research is accessed by the design teams using the opportunities available to them. Only the clinicians have direct access to published research, other members of the design team did not subscribe to any peer reviewed academic journals and instead accessed such evidence through secondary publications, research summaries and databases, examples including research papers, reports and databases published by the Department of Health and Social Care and other institutions. Summarised research contents provide designers with starting points as well as design evaluation criteria. For instance, design teams are aware of findings from the key reviews such as Ulrich (2008). Further, there is a strong interest in attending healthcare design conferences by all the parties involved in the development of hospitals. Whilst built environment professionals regularly attend trade and academic conferences, client representatives with the clinical background only attend the conferences when they are involved in a hospital development project. The two most significant examples of published EBD researches were the single-patient room design and decentralised nursing station design (found in all Case Studies), yet these are highly prominent examples of EBD interventions in practice and so could have reached the designers through various means and a well lubricated flow. Indeed, Case Study 2 was itself part of a pilot project of the National Health Service in Wales to investigate wide implementation of single patient rooms in Wales, and was visited by Professor Roger Ulrich (as in Ulrich et al., 2008) himself. However despite this favourable position for Case Study 2, published research evidence did not form a more prominent source in comparison to the other Case Studies. Due to the limited time available to procure Case Study 3, instances of using published research evidence or internally generated evidence could not be found at all within the selected design elements, suggesting the barrier to flow was in this case too large to overcome in practice. This research to a large extent revalidated previous work (Emmitt, 2007; Neuckermans \& Fontein, 2002; Tetreault \& Passini 2003) by revealing that published peer reviewed research is still not the primary source of evidence in healthcare 
design, suggesting a barrier to its flow. Converting peer reviewed published research into research summaries (as proposed by Martin \& Guerin, 2007) and design frameworks based on systematic reviews as suggested by Van-Hoof et al. (2015) are easy to access and digest within the tight time and resource constraints. Designers' research skills related to search and understand evidence as mentioned in the previous literature (Martin \& Guerin, 2007; Lawson, 2010; Chen et al., 2011) is a lower barrier ) when the team has indirect access to researchers through collaborations with research institutions and through the team members who engage in research activities for career development. In this context, providing designers with literature search skills, training and facilities (Martin \& Guerin, 2006; Edelstien, 2008; Stichler, 2010) would be less attractive compared to utilising indirect opportunities to employ research skills and access to the project. When such opportunities are not available employing a researcher or an external party as suggested by Codinhoto et al (2010) and Freihoefer \& Zborowsky (2017) depending on the resource availability. Design teams possess basic research skills such as awareness of context bounded nature of research evidence and ability to critique. Advanced research skills related to assess credibility of evidence or strength of evidence (as discussed in Stichler 2010, Pati 2011) are less pertinent since design teams extensively evaluate the suitability of evidence collectively from all the sources during the evaluation of design solutions as oppose to evaluating the credibility of individual evidence. Therefore, guidance to improve application of evidence effectively with due consideration into the contextual aspects (Wanigarathna et al., 2019); guidance to conduct mock up simulations (Durham \& Kenyon, 2020) and supporting tools such as Design diagnostics (Nanda \& Wingler, 2020) are more effective and practical compared to empowering designers with advanced research skills. Such guidance and tools could help with the resource constraints (Codinhoto et al., 2010) and challenges related to managing views and expectations from multiple stakeholders by providing design teams with advance skills and structured approaches (Hignett \& Lu, 2009) to perform primary design activities related to design evaluation. 


\section{Internally Generated Research}

Figure 4 reveals that, with the exception of Case Study 3, evidence from internal research conducted at the project level and within supply chain organisations is used to the same extent as evidence from any other source, suggesting a lower barrier and an easier flow than that faced by published research. Some purposive research was undertaken for project specific problems such as design of an innovative hot and cold water supply system (for Case Study 1), performance modelling (eg: thermal comfort modelling within single rooms in Case Studies 1 and 2) and for case specific engineering systems. Robust research results were generated through the use of physical mock-ups of single patient rooms in Case Studies 1 and 2. Case Study 1 also used enabling works (temporary accommodation used to maintain healthcare provision during the construction works) as a means to test some new products and systems before they were applied to the permanent buildings. Case Study 1 (an extension to an existing hospital) was in a favourable position to conduct internal research, and clinical staff from the existing hospital, infection control staff, and facilities management staff were all involved in generating new evidence to be used in the construction of the extension. Collaborations with research institutions and their involvement in research activities aid to improve the credibility of the internal research to a certain extent. In addition, these collaborative research improve design team members' research skills as well as improve the EBD knowledge base by improving the robustness of the practice based research (Zborowsky \& BunkerHellmich, 2010). However, such practice-based research mostly remained within the stakeholder organisations directly involved in the project, thus limiting its flow beyond that group of designers. These findings confirm the prospect of designer involved internal research to facilitate EBD (works such as Becker and Carthers (2007) and Freihoefer \& Zborowsky (2017). As expected by Freihoefer \& Zborowsky (2017), such practice-based research improve design professions' body of knowledge who have limited opportunities to conduct robust post-occupancy evaluations. Even though resource limitations such as skills, time and cost may possibly impede the opportunity to generate 
robust findings to the same standards as those carried out at research institutions, such research is better able to flow into new design solutions as well as to apply existing solutions to new contexts.

\section{Industry Evidence}

With regard to the other sources of evidence used, findings revealed that evidence from industry was mainly used during the detail design phase, and more specifically in relation to off-site built elements such as glass observations panels for doors (in all Case Studies); bed head services panels (in Case Studies 2 \& 3); and computers at nurse station (in Case Studies 1 \& 2). In many instances, the adopted/adapted solutions were successful due to extensive evaluation steps and subsequent improvements made as necessary. As Gann et al., (1998) claim, it is therefore possible that material and component producers actually carry out the majority of construction-related research, and more of them could be used to design context specific solutions.

\section{Design Standards and Guidance}

Design standards and guidance are well accepted by design teams and trusted as baseline guidance for clients' representatives who are less familiar with designs and flow relatively easily into designs, irrespective of the weaknesses. Prescriptive solutions (such as exemplar layouts for private patient room) contained in the standards and guidance are used as a starting points and they are then modified to suit the contextual circumstances based on the other sources of evidence such as user consultation. The continuation and ongoing development of such guidance is therefore important. To capitalise on this ease of flow, providing a wider ownership of building design quality standards throughout the supply chain with interdisciplinary expertise as proposed by Mills et al. (2015) could therefore be effective in the overall enhancement of EBD. For example, quarterly or monthly briefing bulletins may be used to disseminate innovative solutions and case studies based on the research conducted by supply chain partners. Design teams could then could adopt suitable solutions after duly evaluations. 


\section{Conclusions}

This research investigated the sources and flow of EBD in the design of healthcare environments.

Findings reveal that healthcare design teams use evidence from various sources, the knowledge and experience of the members of the design team is the most common and flows the most easily.

Despite its 'validity', our findings confirmed that peer reviewed published research is not the primary source of evidence to facilitate EBD in current contexts, and does not flow well into designs in its initial form. Yet, they flow better when converted into other forms such as research summaries and underpin design standards and guidance Complexities in healthcare designs, the nature of stakeholders including their familiarity with built environment designs, and resource constraints influence EBD practices in practice. The flow of research evidence into the design can be effectively facilitated via proactively including members with research skills or collaborators such as research institutes to overcome flow issues associated with the medium of communication. Such collaborations could also better facilitate robust practice-based research at project level and within the supply chain partner organisations, improve design team members research skills and knowledge bases, and therefore fundamentally contribute to the credible research that forms the EBD evidence base.

This research used retrospective evidence of EBD practices as told by the members of the design team. Whilst efforts were made to improve the comprehensiveness and validity of data through triangulation, further research is required to better understand how flow becomes design in practice, and thus enable the continued enhancement and adoption of EBD interventions in practice.

\section{Acknowledgements/ Funding details/ Disclosure statement}

This is included within the cover page; here after the peer review. 


\section{References}

Becker, F. and Cartheies, J. (2007). Evidence-Based healthcare facility design: Key issues in collaborative process, CIB W092 2007 Interdisciplinary in Built Environment Procurement 2007, pp. 23-26.

Benitez, G.B., Da-silveira, G.J. and Fogliatto, F.S. (2019). Layout Planning in Healthcare Facilities: A Systematic Review. HERD: Health Environments Research \& Design Journal, 12(3),pp.31-44.

Brambilla, A. and Capolongo, S. (2019). Healthy and Sustainable Hospital Evaluation-A Review of POE Tools for Hospital Assessment in an Evidence-Based Design Framework. Buildings, 9(4),pp.76.

Chen, B., Phiri, M., Mills, G., Price, A.D.F. and Austin, S. (2011). Healthcare Infrastructure Design in the UK: Guidance, Standards, Tools and PAMs, HaCIRIC conference 2011, September 20112011.

CENTER FOR HEALTH DESIGN, 2020-last update, Pebble project from the center for health design [Homepage of healthdesign.org], [Online]. Available: https://www.healthdesign.org/researchservices/pebble-project [December, 2020].

Codinhoto, R., Platten, B., Tzortzopoulos, P. and Kagioglou, M. (2010). Supporting Evidence-based Design. In: M. KAGIOGLOU and P. TZORTZOPOULOS, eds, Improving Healthcare through Built Environment Infrastructure. 2 edn. Willey Blackwell, pp.151-165.

Codinhoto, R., Tzortzopoulos, P., Kagioglou, M., Aouad, G. and Cooper, R. (2009). The impacts of the built environment on health outcomes. Facilities, 27,3(4),pp.138-151.

DH ESTATES AND FACILITIES DIVISION (2008). A Staff and Patient Environment Calibration Toolkit (ASPECT). Leeds: DH Estates and Facilities Division.

Devlin, A.S. and Arneill, A.B. (2003). Health care environments and patient outcomes. Environment and Behavior, 35(5),pp.665-694.

Durham, J. and Kenyon, A. (2019). Mock-ups: Using experiential simulation models in the healthcare design process. HERD: Health Environments Research \& Design Journal, 12(2),pp.11-20.

Edelstein, E.A. (2008). Searching for evidence. Herd, 1(4),pp.95-110.

Elf, M., Frost, P., Lindahl, G. and Wijk, H. (2015). Shared decision making in designing new healthcare environments - time to begin improving quality. BMC health services research, 15(1),pp.114.

Emmitt, S. (2007). Design management for architects. London: Wiley-Blackwell.

Evans, B. (2010). Evidence Based Design. In: L. LEE \& P. LOMBAERDE, eds, Bringing the World into Culture: Comparative Methodologies in Architecture, Art, Design and Science. Academic \& Scientific Publishers, pp.227-239.

Fay, L., CAI, H. and REAL, K. (2019). A systematic literature review of empirical studies on decentralized nursing stations. HERD: Health Environments Research \& Design Journal, 12(1),pp.4468. 
Gann, D.M., Wang, Y. and Hawkins, R. (1998). Do regulations encourage innovation?-the case of energy efficiency in housing. Building Research \& Information, 26(5),pp.280-296.

Grol, R. and Grimshaw, J. (2003). From best evidence to best practice: effective implementation of change in patients' care. The Lancet, 362(9391), pp. 1225-1230.

Hamilton, D.K. (2003). The four levels of evidence-based practice. Healthcare Design, 3(4), pp. 18-26.

Hamilton, K., \& Watkins, D.H. (2009). Evidence based design for multiple building types. USA: John Wiley and Sons.

Hamilton, D.K. (2010). Reflecting on Three Decades of Practice: where's the Rigor? Health Environments Research and Design Journal, 4(1),pp.89-94.

Hamilton, D.K. (2018). Progress: From research to best practice. Health Environments Research and Design Journal, 11(4),pp.33-36.

Hanc, M., Mcandrew, c. and Ucci, M. (2019). Conceptual approaches to wellbeing in buildings: a scoping review. Building Research \& Information, 47(6),pp.767-783.

Hignett, S. and Lu, J. (2009). An investigation of the use of health building notes by UK healthcare building designers. Applied Ergonomics, 40(4),pp.608-616.

Lawson, B. (2010). Healing architecture. Arts \& Health, 2(2),pp.95-108.

Martin, C. and Guerin, D. (2007). Integrating the Use of Research into the Design Process Experience. IDEC 2007, 30(1),pp.57-67.

Martin, C.S. and Guerin, D.A. (2006). Using research to inform design solutions. Journal of Facilities Management, 4(3),pp.167-180.

Mills, G.R., Phiri, M., Erskine, J. and Price, A.D. (2015). Rethinking healthcare building design quality: an evidence-based strategy. Building Research \& Information, 43(4),pp.499-515.

Moore, K.D. and Geboy, L. (2010). The question of evidence: current worldviews in environmental design research and practice. Architectural Research Quarterly, 14(02),pp.105-114.

Nanda, U. and Wingler, D. (2020). Practice-Based Research Methods and Tools: Introducing the Design Diagnostic. HERD: Health Environments Research \& Design Journal, 13(4),pp.11-26.

Neuckermans, H. and Fontein, L. (2002). Nurture and nature of research in architecture, ARCC/EAAE Montreal conference on architectural research proceedings 2002, pp.23-29.

Pati, D. (2011). A framework for evaluating evidence in evidence-based design. HERD: Health Environments Research \& Design Journal, 4(3),pp.50-71.

Phiri, M. (2006). Does the physical environment affect staff and patient health outcomes? A review of studies and articles 1965-2006. DH. London, TSO.

Riffe, D., Lacy, S., Fico, F. and Watson, B. (2019). Analyzing media messages: Using quantitative content analysis in research. Routledge. 
Sailer, K., Budgen, A., Lonsdale, N., Turner, A. and Penn, A. (2010). Pre and Post Occupancy Evaluations in Workplace Environments. The Journal of Space Syntax, 1(1),pp.199-213.

Stichler, J.F. (2010). Research or Evidence-Based design: Which process should we be using? Health Environments Research and Design Journal, 4(1),pp.6-10.

Tetreault, M.H. and Passini, R. (2003). Architects' use of information in designing therapeutic environments. Journal of Architectural and Planning Research, 20(1),pp.48-56.

Taylor, E., Card, A.J. and Piatkowski, M. (2018). Single-occupancy patient rooms: a systematic review of the literature since 2006. HERD: Health Environments Research \& Design Journal, 11(1),pp.85-100.

Voigt, J., Mosier, M. and Darouiche, R. (2018). Private rooms in low acuity settings: a systematic review of the literature. HERD: Health Environments Research \& Design Journal, 11(1),pp.57-74.

Ulrich, R.S., Zimring, C.M., Zhu, X., Dubose, J.R., Seo, H.B., Choi, Y.S., Quan, X. \& Joseph, A. (2008). A review of the research literature on evidence-based healthcare design. Health Environments Research \& Design, 1(3),pp.61-125.

Ulrich, R.S., Berry, L.L., Quan, X. and Parish, J.T. (2010). A conceptual framework for the domain of Evidence based design. Health Environments Research \& Design, 2010(Fall), pp.95-114.

van-Hoof, J., Rutten, P.G., Struck, C., Huisman, E.R. and Kort, H.S. (2015). The integrated and evidence-based design of healthcare environments. Architectural Engineering and Design Management, 11(4),pp.243-263.

Wanigarathna, N., Sherratt, F., Price, A. and Austin, S. (2019). Design re-use: critical application of healthcare building design evidence. Engineering, Construction and Architectural Management, 26 (3),pp.350-366.

Authors (2012) A conceptual model of evidence based design for healthcare in the UK. HaCIRIC International Conference 2012. September 19-21, 2012, HaCIRIC.

Zborowsky, T. and Bunker-Hellmich, L. (2010). Integrating healthcare design research into practice: Setting a new standard of practice. HERD: Health Environments Research \& Design Journal, 4(1),pp. 115-130.

Zhang, Y., Tzortzopoulos, P. and Kagioglou, M. (2019). Healing built-environment effects on health outcomes: Environment-occupant-health framework. Building Research \& Information, 47(6),pp.747-766. 